\title{
Socialitation and Simulation Game of the Volleyball Sand Sport in Babar Islands District of Southwest Maluku Regency
}

\author{
Mieke Souisa ${ }^{1}$, Jacob Anaktototy ${ }^{2}$, Jusak Syaranamual ${ }^{3}$ \\ 1, 2, 3Pattimura University Ambon \\ Email: 1ms.souisa1512@gmail.com, 2jopi.anaktototy18@gmail.com,3jusakambon@gmail.com \\ doi https://doi.org/10.36526/gandrung.v2i2.1384
}

\begin{abstract}
Since 1996 the volleyball sand sports have developed in Maluku province, and there has been vocation in PON as well as being one of the regular sport events of the province Maluku. But volleyball sand sport is known only to a view counties and cities in Maluku province. Such the cities of Southeast Maluku (Tual), the Regency of Tanimbar Island (Saumlaki), the Regency of Buru Island (Namlea), and Ambon City. But in Southwest Regency (Moa), the volleyball sand sports is now means to know until this day. Than Southwest Regency MOA has never include the sport branch in both the POPMAL administration and the state of the region. Event without it's being recognized as a means of development for the regency of Southwest Maluku. Babar Islands is one of the sub district in Maluku Southwest, it is far from the capital of Southwest Regency (MOA) and Maluku Province. It is a analized factor in the development of the volleyball sand sport branch on Kalwedo Earth. Thus community service activities that embody the volleyball basic skills by college of the academy of arts and sciences, perform devotionals aimed at introducing a volleyball sand sport to the community and those responsible. The method uses for achieving goals in this community service is: 1) identification problem, 2) social approach, 3) planning, 4) administration management, 5) matrial preparation, 6) execution, 7) reporting. The results is: 1) participants of both the sons and doughters volleyball and the socialist-in volved volleyball. 2) participants understand the rules of volleyball sand game. 3) entry to the games own game. 4) the means and infrastructure of the game's of the volleyball games. 5) the volleyball sand sport and infrastructure help during public service activities by lecture and collages of study programe physical education in Babar Islands
\end{abstract}

Keyword: Socialitation, Games, Simulation, Matches, Sand Volleyball

\section{Pendahuluan}

Tri Dharma Perguruan Tinggi merupakan tiga hal pokok yang wajib dilaksanakan dan dikembangkan secara berkesinaambungan diseluruh unsur sivitas akademika, diantaranya dosen dan juga mahasiswa. Tri dharma inipun bukan hanya sebuah slogan saja, namun haruslah menjadi budaya yang harus disadari dan terinternalisasi bagi seluruh civitas akademika, sehingga cita-cita sebenarnya dari sebuah tri dharma perguruan tinggi dapat terwujud dan terimplementasikan dengan baik.

Pengabdian masyarakat merupakan unsur ketiga setelah unsur pertama; pendidikan, serta unsur kedua; penelitian dan pengembangan dari Tri Dharma Perguruan Tinggi, dan sepenuhnya akan dilaksanakan oleh seluruh civitas akademika sesuai bidang kompetensi. Terjun dan berinteraksi secara langsung ke masyarakat merupakan salah satu hal strategis dalam mengembangkan kegiatan yang 
GANDRUNG: Jurnal Pengabdian Kepada Masyarakat ISSN: 2721-6136 (Online)

diharapkan dapat berdampak positif bagi masyarakat. Berdasarkan aura dari pengabdian kepada masyarakat inilah, maka para dosen dan juga mahasiswa prodi penjaskesrek yang memiliki kompetensi dalam cabang olahraga bolavoli melaksanakan kegiatan bagi masyarakat yang sesuai dengan kompetensi matakuliah keterampilan dasar bolavoli, berupa "Sosialisasi serta simulasi pertandingan bolavoli pasir" di kecamatan Pulau-Pulau Babar Kabupaten Maluku Barat Daya.

Permainan bolavoli pasir merupakan salah satu nomor pada cabang olahraga prestasi bolavoli, yang telah masuk dan berkembang pesat di Indonesia umumnya, dan juga di Maluku khususnya, sejak tahu 1993. Bahkan record dari cabang olahraga ini telah berbicara di tingkat Internasional. Demikian pula di Maluku, Maluku juga pernah berkiprah hingga ke tingkat Nasional bahkan internasional. Namun sayang sudah 2 (dua) periode, induk organisasi olahraga bolavoli di Maluku tidak berfungsi atau tidak aktif, sehingga sampai dengan saat ini pengurus provinsi sama sekali tidak bergerak untuk memperhatikan pengembangan prestasi cabang olahraga ini.

Di Maluku cabang olahraga bolavoli pasir telah dipertandingkan melalui pelaksanaan pekan olahraga provinsi Maluku sejak tahun 2007, namun hanya dikenal oleh beberapa kabupaten, seperti Kota Tual, Maluku tenggara, Maluku Tenggara Barat, Pulau Buru, serta kota Ambon. Namun sampai saat ini, beberapa kabupaten di Provinsi Maluku sama sekali belum tersentuh oleh pembinaan olahraga ini. Demikian pula kabupaten Maluku Barat Daya belum pernah mengikut sertakan cabang olahraga ini baik di pelaksanaan Pekan Olahraga Provinsi Maluku (POPMAL) maupun kejuaraan Daerah, padahal tanpa disadari letak geografis dan keadaan alam yang digunakan sebagai sarana pengembangan cabang olahraga ini dimiliki oleh kabupaten Maluku Barat Daya. Kecamatan pulau-pulau Babar merupakan salah satu kecamatan di kabupaten Maluku Barat Daya, merupakan salah satu pulau terluar, karena letaknya yang jauh dari pusat kota kabupaten dan provinsi, dianalisis merupakan faktor penghambat pengembangan cabang olahraga bolavoli pasir di bumi Kalwedo (Gambaran Umum Kondisi Wilayah Maluku Barat Daya, 2018)

Oleh karenanya program studi pendidikan jasmani kesehatan dan rekreasi, melalui panitia pengabdian kepada masyarakat kolaborasi mahasiwa dan dosen program studi, ingin mengenalkan cabang olahraga bolavoli pasir melalui kegiatan sosialisasi peraturan permainan sekaligus melaksanakan pertandingan, agar cabang olahraga bolavoli pasir kedepan dapat berkembang ditanah Kalwedo. 
GANDRUNG: Jurnal Pengabdian Kepada Masyarakat ISSN: 2721-6136 (Online)

\section{Metode}

Tahapan pelaksanaan dalam kegiatan Sosialisasi permainan dan simulasi pertandingan bolavoli pasir di Kecamatan Pulau-Pulau Babar Kabupaten Maluku Barat Daya, dilalui dengan tahapan sebagai berikut: (1) Identifikasi Masalah, (2) Pendekatan Sosial, (3) Perencanaan, (4) Manejemen Administrasi, (5) Persiapan Matrial, (6) Pelaksanaan. dan (7) Pelaporan. Tahapan-tahapan tersebut dapat dijelaskan sebagai berikut:

1. Identifikasi Masalah

Identifikasi masalah merupakan tahapan yang harus dilalui dalam Menyusun sebuah kegiatan ilmiah. Demikian pula dalam sebuah kegiatan yang dilakukan untuk kepentingan masyarakat. Seperti yang telah dikemukakan sebelumnya. Oleh karena itu, setelah mencermati perkembangan cabang olahraga bolavoli pantai yang hingga kini belum tersosialisasi dengan baik pada hamper sebagian kabupaten di provinsi tercinta ini, maka berdasarkan keputusan Bersama dosen pengampu matakuliah keterampilan dasar bolavoli, serta Unit Kegiatan Mahasiswa (UKM) bolavoli indoor dan pantai, memutuskan perlu dilaksanakannya kegiatan pengabdian kepada masyarakat, agar permainan bolavoli pantai dapat dikenal di kecamatan ini.

2. Pendekatan Sosial

Setelah tim pengabdian ditentukan melalui mekanisme perkuliahan keterampilan dasar bolavoli, maka tim tersebut diusulkan ke program studi dalam hal ini ketua program studi (kaprodi), kemudian Kaprodi pun melakukan koordinasi dengan pimpinan Fakultas, dalam rangka pelaksanaan PKM dari matakuliah keterampilan dasar bolavoli, dan hal tersebut disetujui oleh pimpinan fakultas yang direalisasikan dalam Surat Keputusan pimpinan fakultas, Nomor: 71/UN13.1.3/SK/2019, tentang "pengangkatan panitia pengabdian kepada masyarakat kolaborasi dosen dan mahasiswa program studi penjaskesrek FKIP Unpatti tahun 2019" serta Surat Tugas Dekan FKIP Unpatti, Nomor: 3176/UN13.1.3.1/KP/2019, dan selanjutnya kamipun melakukan berbagai proses berkelanjutan, agar tujuan yang telah ditetapkan Bersama dapat tercapai. Beberapa kegiatan yang dilakukan antaralain;

a. Berdasarkan surat pemberitahun yang dikeluarkan oleh pimpinan Fakultas, nomor: 2604/UN13.1.3/KP/2019 tentang "penyampaian kegiatan pengabdian" yang akan berlangsung di Kecamatan PP. Babar, maka perwakilan tim pengabdian pun Melakukan Sosialisasi dengan pemerintah kecamatan Pulau-Pulau Babar, untuk menyampaikan maksud dan tujuan dari kegiatan pengabdian kepada masyarakat di Kecamatan Pulau-Pulau Babar. 
b. Sosialisasi kepada para Pemerhati olahraga dan para pembina serta pelatih klub bolavoli, para guru pendidikan jasmani yang turut membina klub bolavoli pada sekolah-sekolah di kecamatan pulau-pulau Babar, Babar Timur, dan Pulau Wetang, terkait dengan maksud dan tujuan dari kegiatan pengabdian dimaksud.

3. Perencanaan

Berdasarkan hasil pendekatan dengan pemerintah kecamatan, pemerintah desa, dan para pembina klub-klub olahraga bolavoli serta para guru pendidikan jasmani yang melaksanakan pembinaan bolavoli pada masing-masing sekolah menengah atas, maka tim pengabdian mulai mempersiapkan berbagai hal, diantaranya membuat spanduk dan juga baliho untuk dipasang di kecamatan Pulau-Pulau Babar, dan sekitarnya. Sebagai bentuk promosi sekaligus menarik perhatian dari para pemain bolavoli dari setiap desa ataupun klub yang ada di kecamatan pulaupulau babar dan sekitarnya.

4. Manejemen Administrasi

Setelah kegiatan ini disebarluaskan maka tim pun menyiapkan berbagai administrasi terkait dengan pendaftaran regu putera dan puteri dari setiap klub bolavoli yang ada di kecamatan pulaupulau Babar dan sekitarnya. Sehingga berdasarkan pendaftaran yang dilakukan, maka sejumlah pasangan bolavoli pasir putera dan puteri dari berbagai klub yang berasal dari klub, desa, maupun instansi dan sekolah.

Adapun tim yang terdaftar berjumlah 34 (tiga puluh empat), dengan rincian; 25 (dua puluh lima) pasang putera, dan 9 (Sembilan) pasang puteri.

5. Persiapan Matrial

Setelah diperoleh 34 (tiga puluh empat) peserta putera dan puteri, selanjutnya sejumlah persiapan pun dilakukan guna memenuhi seluruh kebutuhan sosialisasi dan simulasi permainan. Sehingga yang dipersiapkan yaitu; (1) materi pelatihan dari narasumber, (2) peralatan pertandingan seperti; net bolavoli pantai, besi untuk tiang net, roads, line, dan juga perlengkapan pertandingan seperti; scoring board, scoring table, spidol permanent besar, bendera linesman, payung pantai, ember air besar, gayung serta berbagai kelengkapan lainnya seperti spanduk-spanduk untuk dipasang pada lokasi bertanding, yang dibutuhkan saat pertandingan berlangsung.

Selain perlengkapan dan peralatan bertanding, tim pun harus mempersiapkan seluruh perbekalan bagi seluruh tim pengabdian yang akan berangkat menuju ke kecamatan Pulau-Pulau Babar, Kabupaten Maluku Barat Daya selama 22 (dua puluh dua) hari melakukan perjalanan dan pelaksanaan kegiatan di lokasi pengabdian. 
GANDRUNG: Jurnal Pengabdian Kepada Masyarakat ISSN: 2721-6136 (Online)

6. Pelaksanaan

Pelaksanaan kegiatan terbagi atas 2 (dua) bagian, yaitu (a) Keberangkatan tim pengabdian dari kota Ambon menuju ke Pulau-Pulau Babar, Kabupaten Maluku Barat Daya. (b) Kegiatan inti berupa sosialisasi dan simulasi pertandingan, dan dapat dijelaskan sebagai berikut;

a. Keberangkatan Tim Pengabdian

Rombongan pengabdian kolaborasi mahasiswa dan dosen program studi berangkat menuju ke lokasi pengabdian di Desa Tepa kecamatan PP. Babar kabupaten Maluku Barat Daya pada rabu, 05 Juni 2019 jam 05.00 wit. (pagi), dengan menggunakan transportasi laut KM. Pangrango, dengan jumlah tim pengabdian yang diberangkat adalah sebagai berikut 3 (tiga) dosen tetap, 2 (dua) dosen Non PNS, 15 (lima belas) mahasiswa dari UKM Bolavoli.

Perjalanan dari kota Ambon menuju ke Kecamatan PP. Babar Kabupaten Maluku Barat Daya dilakukan selama 3 (tiga) hari dengan menggunakan KM. Pangrango, ditambah 1 (satu) hari mengalami warning di Pulau Banda karena ketinggian gelombang laut 6 meter, sehingga tim pengabdian tiba di Kecamatan PP. Babar awalnya terjadwal pada 08 Juni 2019, mengalami keterlambatan. maka tim tiba di lokasi pengabdian pada 09 Juni 2019.

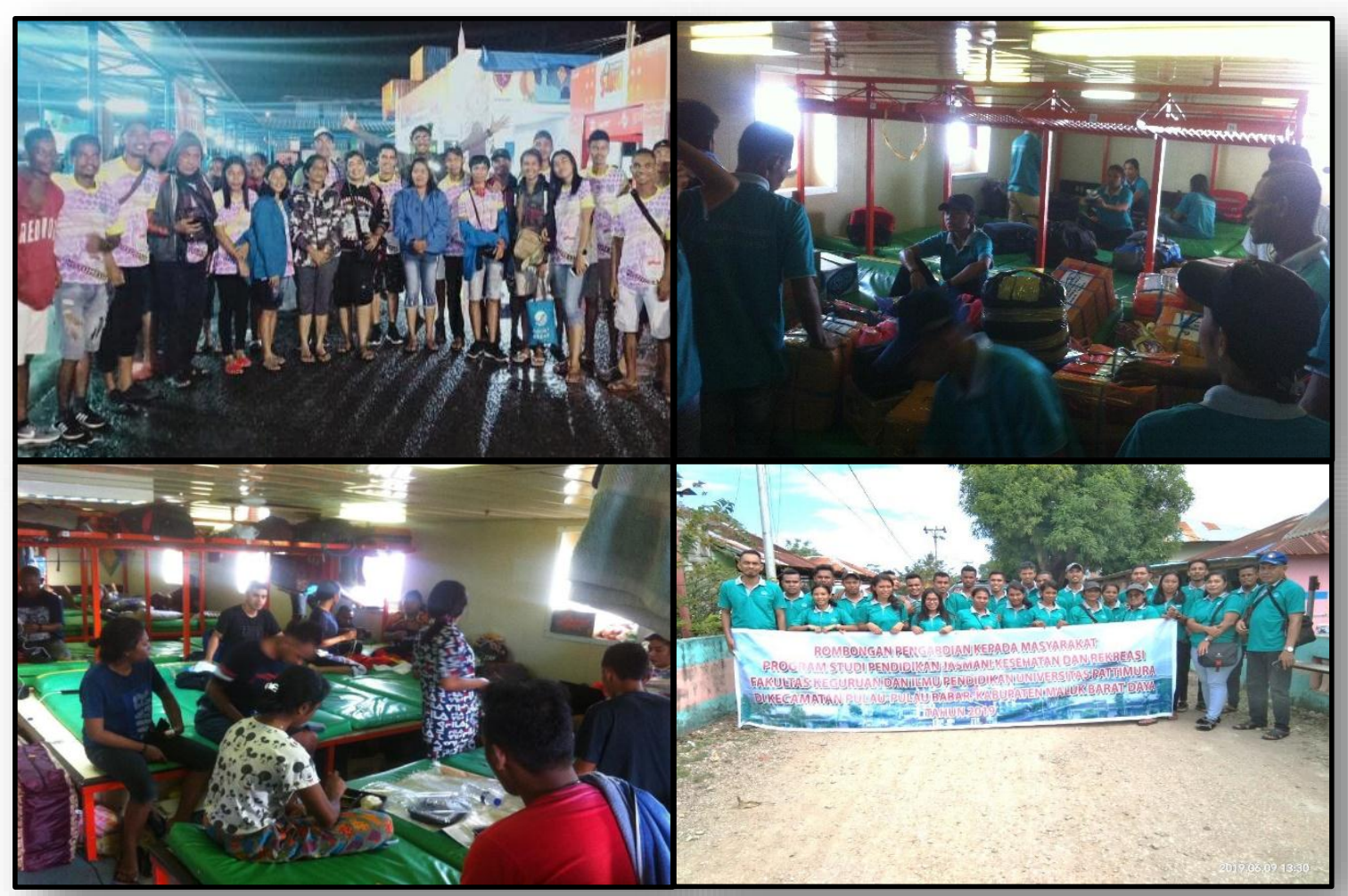

Gambar 1

Rangkaian Perjalanan Tim dari Ambon

Hingga Tiba di Kecamatan PP. Babar Kabupaten Maluku Barat Daya

Dengan KM. Pangrango.

Volume 2, Number 2, Juli 2021| 238

Socialitation and Simulation Game of the Volleyball Sand Sport in Babar Islands District of Southwest Maluku 


\section{b. Persiapan Pelaksanaan Sosialisasi \& Simulasi Pertandingan}

Permainan bolavoli pasir yang akan disosialisasikan dan disimulasikan dalam pertandingan merupakan sesuatu yang baru di daerah ini merupakan sesuatu yang sama sekali belum dikenal oleh para pemain bolavoli maupun para pelatih di daerah ini, sehingga untuk melaksanakan simulasi, perlu diadakannya lapangan bolavoli pantai.

Sehingga sebelum sosialisasi dan simulasi dilaksanakan pada 17, dan 18 - 20 Juni 2019, tim pengabdian haruslah mempersiapkan prasarana berupa lapangan bolavoli pasir. Dan untuk pembuatan lapangan ini, tim harus berkoordinasi untuk menentukan lokasi yang akan disediakan untuk membuat lapangan, mulai dari pengukuran lokasi, penggalian arena lapangan (untuk pengisian pasir pantai disekitar arena) tersebut, juga berkoordinasi dengan pihak swasta untuk kebutuhan penggalian arena lapangan, maupun pengangkutan pasir yang berlokasi di desa Imroing untuk menutupi arena lapangan bolavoli pasir.

Setelah ditetapkan lokasi oleh pemerintah kecamatan dan pemerintah desa, maka tim pun mulai menyiapkan berbagai peralatan maupun bahan untuk kebutuhan pengukuran, penggalian, dan pengerjaan galian lapangan bolavoli pasir yang bertempat di pusat lapangan kalwedo, kecamatan PP. Babar Kabupaten Maluku Barat Daya. Pengerjaan lapangan dilaksanakan selama 7 (tujuh) hari, yaitu mulai dari tanggal 10 Juni 2019 s.d 16 Juni 2019, secara jelas tergambar dalam table 1 dibawah ini. Selain menyiapkan sarana, tim juga harus mempersiapkan proses pendaftaran yang terdiri dari 2 (dua) tahap. Yaitu; (1) Pendaftaran tim, dan (2) Pendaftaran nama pemain.

Tabel 1.

Uraian Kegiatan Pengerjaan Lapangan Bolavoli Pasir "LEKWAKI"

\begin{tabular}{|c|c|c|c|c|}
\hline \multicolumn{2}{|c|}{ Hari/Tanggal } & \multicolumn{2}{|r|}{ Uraian Pengerjaan } & \multirow{2}{*}{$\begin{array}{c}\text { Keterangan } \\
\text { Mahasiswa \& Dosen. }\end{array}$} \\
\hline Minggu, & $\begin{array}{l}\text { 09 Juni } \\
2019\end{array}$ & 1. & $\begin{array}{l}\text { Pengukuran arena atau lokasi ukuran } 23 x \\
14 \text { meter. }\end{array}$ & \\
\hline Senin, & $\begin{array}{l}10 \text { Juni } \\
2019\end{array}$ & 2. & $\begin{array}{l}\text { Pengukuran arena lapangan bolavoli pasir, } \\
\text { ukuran } 8 \times 16 \text { meter. }\end{array}$ & Mahasiswa \& Dosen. \\
\hline $\begin{array}{l}\text { Selasa, } \\
\text { s.d } \\
\text { Kamis }\end{array}$ & $\begin{array}{c}\text { 11 Juni } \\
2019 \\
\text { s.d } \\
13 \text { Juni } \\
2019\end{array}$ & 3. & Penggalian arena pertandingan. & $\begin{array}{l}\text { Mahasiswa \& Dosen, Perusahaan, } \\
\text { Pemerintah Kecamatan. }\end{array}$ \\
\hline Jumat, & $\begin{array}{l}14 \text { Juni } \\
2019\end{array}$ & 4. & $\begin{array}{l}\text { Pengambilan pasir pantai di lokasi } 1 \text { (pasir } \\
\text { panjang) }\end{array}$ & Mahasiswa, Dosen, Perusahaan. \\
\hline $\begin{array}{l}\text { Sabtu, } \\
\text { s.d } \\
\text { Minggu, }\end{array}$ & $\begin{array}{l}15,16 \text { juni } \\
2019\end{array}$ & 5. & $\begin{array}{l}\text { Pengambilan pasir pantai di lokasi } 2 \\
\text { (pantai desa Tela), Kec. PP. Babar. }\end{array}$ & Mahasiswa, Dosen, \& Pengusaha. \\
\hline
\end{tabular}


GANDRUNG: Jurnal Pengabdian Kepada Masyarakat ISSN: 2721-6136 (Online)

\begin{tabular}{|c|c|c|l|c|}
\hline & & & $\begin{array}{l}\text { Serta pengisian pasir di arena } \\
\text { pertandingan. }\end{array}$ & \\
\hline Senin, & $\begin{array}{c}17 \text { Juni } \\
2019\end{array}$ & 6. & $\begin{array}{l}\text { Penyiapan (finishing) arena dan lapangan } \\
\text { pertandingan bolavoli pasir. }\end{array}$ & $\begin{array}{c}\text { Mahasiswa, dosen, \& pihak } \\
\text { kecamatan. }\end{array}$ \\
\hline
\end{tabular}

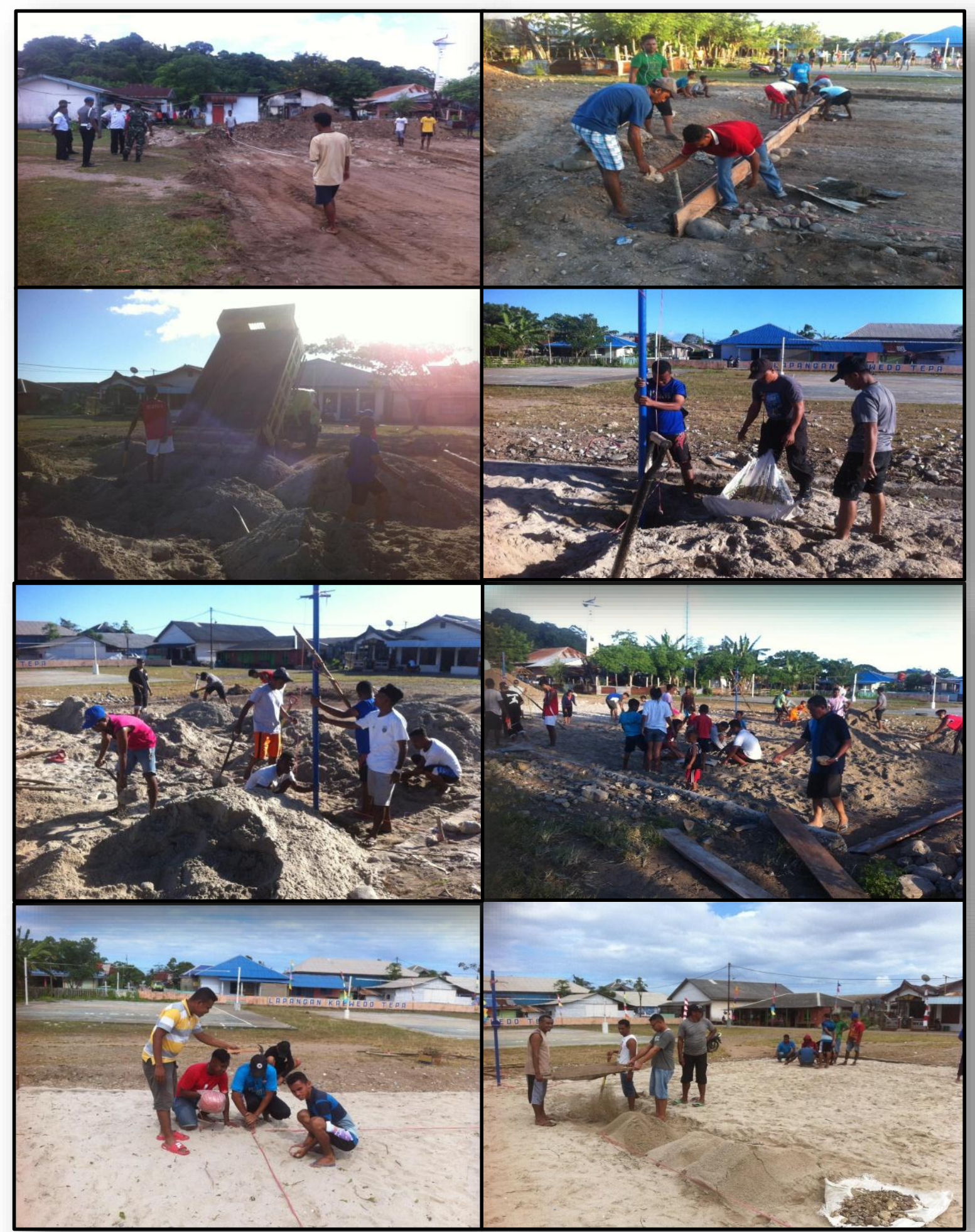

Gambar 2. Membuat Lapangan Bolavoli Pasir Bersama Pemerintah setempat, Koramil, Polsek dan Masyarakat Bertempat di Lapangan Kalwedo, Desa Tepa.

Volume 2, Number 2, Juli $2021 \mid 240$

Socialitation and Simulation Game of the Volleyball Sand Sport in Babar Islands District of Southwest Maluku 


\section{c. Pelaksanaan Sosialisasi}

Sosialisasi peraturan permainan yang harus dilakukan oleh para pemain, sekaligus sosialisasi peraturan pertandingan, merupakan kegiatan yang harus dilaksanakan oleh panitia pengabdian kolaborasi bagi para pemain bolavoli yang telah terdaftar sebagai peserta dalam pertandingan bolavoli pasir, oleh karena permainan ini sama sekali belum tersentuh bahkan dikenal sama sekali oleh masyarakat olahraga bolavoli di kecamatan ini. Bahkan membayangkan permainan yang dilakukan menggunakan bola yang bagaimana bentuknya pun sama sekali belum pernah. Sehingga mengawali rangkaian pertandingan, perlu dilaksanakan sosialisasi terkait bagaimana permainan ini harus dimainkan, dan bagaimanakah bentuk-bentuk peraturan pertandingan yang harus dipahami oleh para pemain. Sehingga dalam kegiatan sosialisasi ini, disajikan beberapa materi antara lain: (1) Bolavoli pasir dan perkembangannya, serta berbagai teknik dalam permainan bolavoli pasir, (2) Manajemen pertandingan. (3) Peraturan pertandingan bolavoli pasir, dan (4) Simulasi pertandingan Bolavoli pasir. Selanjutnya sosialisasi terkait dengan materi permainan bolavoli pasir yang telah diuraikan diatas, dilaksanakan pada tanggal 17 Juni 2019.

d. Pelaksanaan Simulasi

Simulasi pertandingan merupakan tahap kegiatan dimana setelah seluruh materi yang disajikan dalam sosialisasi pada hari senin, tanggal 17 Juni 2019 diterima maka peserta akan mempraktekkan atau mengimplementasikan materi-materi tersebut, mulai dari rangkaian pertemuan teknis, maupun sampai pada tahap pertandingan dilaksanakan, mulai dari rangkaian babak penyisihan, babak semifinal, dan babak final. Dan simulasi pertandingan ini sendiri dilaksanakan pada tanggal 18, 19, dan 20 Juni 2019.

Berdasarkan tabel entry form by team dan entry form by name, maka jumlah peserta yang terlibat dalam kegiatan ini sebanyak 27 (dua puluh tujuh) pasang putera, dan 9 (Sembilan) pasang puteri, yang berasal dari klub-klub bolavoli di kecamatan PP. Babar, kecamatan Babar Timur, dan kecamatan pulau wetang. Dengan rangkaian pertandingan sebanyak 26 (dua puluh enam) pertandingan untuk putera, dan 8 (delapan) pertandingan untuk puteri. Sehingga jumlah pertandingan yang dapat direncanakan oleh panitia sebanyak 34 (tiga puluh empat) pertandingan, dan dilaksanakan selama 3 (tiga) hari. Sedangkan system pertandingan yang digunakan yaitu "system gugur" menggunakan for ronde, dengan system permainan "two winning set". 


\section{e. Pelaporan}

Pelaporan merupakan tahap penyampaian hasil pelaksanaan seluruh rangkaian kegiatan pengabdaian kepada masyarakat, mulai dari perencanaan hingga akhir seluruh rangkaian pelaksanaan kegiatan.

\section{Hasil dan Diskusi}

Berdasarkan tahapan yang dilalui dalam seluruh tahapan pelaksanaan kegiatan pengabdian kepada masyarakat, maka pengabdian masyarakat merupakan suatu kegiatan yang diharapkan dapat memberi dampak positif sebagai berikut: Berdasarkan pendekatan sosial yang dilakukan oleh tim PKM, dengan pihak pemerintah dalam hal ini pemerintah kecamatan Pulau-Pulau Babar Kabupaten Maluku Barat Daya dan pemerintah desa Tepa, serta para pembina olahraga umumnya dan khususnya cabang olahraga bolavoli, guru pendidikan Jasmani pada jenjang sekolah menengah pertama dan sekolah menengah atas, dan seluruh pemain bolavoli di kecamatan ini, berhasil mendaftarkan 26 (dua puluh enam) pasang putera dan 9 (Sembilan) pasang puteri, yang dapat terlihat dalam tabel 2 dibawah ini.

Tabel 2.

Entry Form By Name Bolavoli Pasir Putera

\begin{tabular}{|c|c|c|c|c|}
\hline No. & Nama Klub & \multicolumn{2}{|c|}{ Nama Pemain } & Nama Pelatih \\
\hline 1. & Gengstar & Jeditia Tenggwana & Habel Kuwai Taliak & Natalia Cr. Imasuli, S.Pd. \\
\hline 2. & SMK Bisa & Alexander Etwiory & Jokser B. Netana & Seltiel Taliak \\
\hline 3. & Ralmida-3 & Peter Riyoly & Yapi Rumalewang & Almin Etwiory \\
\hline 4. & Armas-2 & Fernandito Wakim & Melanton Imurnely & Demi \\
\hline 5. & SMP N. One & Rafael Mosse & Estepanus Mosse & Natalia Cr. Imasuly, S.Pd. \\
\hline 6. & Ralmida-1 & Ahaswerus Relmasira & Luter Teurupun & Almin Etwiory \\
\hline 7. & Armas-5 & Yoram Okimekma & Kaleb Okimekma & Demi \\
\hline 8. & Garuda Biru & Jacob Etwiory & Evan Letlora & Rey Mosse \\
\hline 9. & Ralmida-2 & Vano Orno & Cerson Koupun & Almin Etwiory \\
\hline 10. & Armas-3 & Viktor Imarnely & Ricky imnana & Demi \\
\hline 11. & Yalena & Andreas R. Rumtutuly & Sealtiel A.W. Taliak & Yakobus Mosse \\
\hline 12. & Koramil & Wellem Labobar & Frans samangun & D. lambiombir \\
\hline 13. & Smansa-4 & Romario Mosse & Aswerus Mayahy & Rey Mosse \\
\hline 14. & Wati Brother's & Yakobus Mosse & Sandy Fidela & Yapi Romatna \\
\hline 15. & BMM Capem Tepa & Paskalis Malirmasele & Bonefasium Opuly & Yohanis Imnora \\
\hline 16. & Smansa-3 & Tirpena Siletty & Benjamin Kromes & Rey Mosse \\
\hline 17. & Lekrey & Roy Mainasse & Maks Anmama & Rein Mosse \\
\hline 18. & Mostag & Risky S. Mose & Nikodemus Tagarnana & Hamd Aziz \\
\hline 19. & Armas-1 & Waitau Okimekma & Ronaldy Imarnely & Demi \\
\hline 20. & Salju-24 & Juan Etwiory & Satria Nettana & Hendra \\
\hline & & & & \\
\hline
\end{tabular}


GANDRUNG: Jurnal Pengabdian Kepada Masyarakat ISSN: 2721-6136 (Online)

\begin{tabular}{|c|c|c|c|c|}
\hline 21. & Armas-4 & Wempy Okimekma & Charles Okmemera & Demi \\
\hline 22. & Ralmida-4 & Elias Wuarlela & Kokyowi Marsesi & Almin Etwiory \\
\hline 23. & Polsek & Lazarus Laipeny & Fandy Leatemia & Y. Polattu \\
\hline 24. & SMK Pertanian & Aghus Walyana & Desmichel Leunupun & B. Romkeny \\
\hline 25. & ASSC - Ambon & Sugen O. Taliak & William Joostensz & Willy Joostensz \\
\hline 26. & Smansa-2 & Kresdo Letlora & Meyoka Etwiory & Rey Mose \\
\hline
\end{tabular}

Tabel 2. Entry Form By Name Bolavoli Pasir Puteri

\begin{tabular}{|c|l|l|l|c|}
\hline No. & \multicolumn{1}{|c|}{ Nama Klub } & \multicolumn{2}{|c|}{ Nama Pemain } & Nama Pelatih \\
\hline 1. & Smansa-4 & Antoneta Mose & Martha B. Kiryoma & Rey Mose \\
\hline 2. & Lekwaky & Wulandari Taliak & Frenska Latue & Wens Rentanubun \\
\hline 3. & Kendis Smile & Florensia Taliak & Ecevina Tagarnana & Yohanes Taliak \\
\hline 4. & Smansa-1 & Angsina Latulola & Diana Walupy & Rey Mose \\
\hline 5. & Watrupun & Fani Teurupun & Triani Selestina Mose & M. Mose \\
\hline 6. & Lekrey & Fransina Mose & Marthina Mose & Ucok \\
\hline 7. & SMK Bisa & Salomi Unwakoly & Winnye A. Rumtutuly & Seltiel Taliak \\
\hline
\end{tabular}

Para Pembina pelatih, dan atlet yang telah terdaftar bukan hanya berasal dari klub bolavoli yang berada di kecamatan PP. Babar saja, melainkan juga dari kecamatan Babar, bahkan juga dari kecamatan seberang Pulau Wetang, seperti dalam tabel 1 dan 2 diatas.

Berdasarkan peserta yang telah terdaftar diatas, maka tim pengabdian pun melaksanakan sosialisasi bagi para pelatih, dan juga para pemain, serta pemerhati olahraga bolavoli, agar mereka lebih memahami kharakteristik dan juga peraturan permainan bolavoli pasir.

Selanjutnya, materi yang disajikan dalam kegiatan ini antara lain; (a) Manejemen Pertandingan. (b) Bolavoli pasir dan perkembangannya, serta Teknik permainan, (c) Garis-Garis Besar Manajemen Pembinaan Prestasi Olahraga Bolavoli Pasir, (d) Peraturan Pertandingan. Seluruhnya disajikan oleh narasumber yang notabene adalah dosen program studi program studi yang memiliki kompetensi dalam bidangnya, dan terlibat dalam kegiatan pengabdian kepada masyarakat ini. Narasumber tersebut antara lain: 1) Prof. Dr. Jacob Anaktototy, S.Pd., M.Pd. 2) Mieke Souisa, S.Pd., M.Pd. 3) Dr. Jusak Syaranamual, M.Pd., dan 4) Viktor R. H. Apituley, S.Pd., M.Pd. Sehingga distribusi materi dan narasumber lebih rinci dapat dilihat dalam tabel 3 dibawah ini.

Tabel 3. Kurikulum Sosialisasi Peraturan Permainan dan Simulasi Pertandingan Bolavoli Pasir Di Kecamatan PP. Babar kabupaten Maluku Barat Daya.

\begin{tabular}{|l|l|l|l|l|}
\hline Hari/Tanggal & \multicolumn{2}{|c|}{ Materi } & $\begin{array}{c}\text { Alokasi } \\
\text { Waktu }\end{array}$ & Narasumber \\
\hline & 1. & Manejemen Pertandingan. & 180 Menit & Prof. Dr. J. Anaktototy, M.Pd. \\
\hline
\end{tabular}


GANDRUNG: Jurnal Pengabdian Kepada Masyarakat ISSN: 2721-6136 (Online)

\begin{tabular}{|c|c|c|c|c|c|}
\hline \multirow{4}{*}{$\begin{array}{l}\text { Senin, } 17 \text { Juni } \\
2019\end{array}$} & 2. & $\begin{array}{l}\text { a. Bolavoli Pasir dan } \\
\text { Perkembangannya. } \\
\text { b. Teknik dalam } \\
\text { permainan bolavoli } \\
\text { pasir. }\end{array}$ & 120 & Menit & M. Souisa, S.Pd., M.Pd. \\
\hline & 3. & $\begin{array}{lr}\text { Garis-garis } & \text { Besar } \\
\text { Manajemen } & \text { Pembinaan } \\
\text { Prestasi Cabang Olahraga } \\
\text { Bolavoli Pasir. }\end{array}$ & 120 & Menit & Dr. J. Syaranamual, M.Pd. \\
\hline & 4. & $\begin{array}{l}\text { Peraturan Pertandingan } \\
\text { Bolavoli Pasir. }\end{array}$ & 180 & Menit & Viktor H. R. Apituley, S.Pd., M.Pd. \\
\hline & 5. & Pertemuan Teknis & 120 & Menit & $\begin{array}{l}\text { Prof. Dr. J. Anaktototy, M.Pd. } \\
\text { Viktor H. R. Apituley }\end{array}$ \\
\hline $\begin{array}{l}\text { Selasa, } 18 \text { Juni } \\
2019\end{array}$ & 1. & $\begin{array}{l}\text { Simulasi pertandingan } \\
\text { babak penyisihan. }\end{array}$ & 630 & Menit & Panitia Pertandingan \\
\hline $\begin{array}{l}\text { Rabu, } 19 \text { Juni } \\
2019\end{array}$ & 1. & $\begin{array}{l}\text { Simulasi pertandingan } \\
\text { babak penyisihan (lanjutan), } \\
\text { dan babak semifinal. }\end{array}$ & 630 & Menit & Panitia Pertandingan \\
\hline $\begin{array}{l}\text { Kamis, } 20 \text { Juni } \\
2019\end{array}$ & 1. & $\begin{array}{ll}\text { Simulasi } & \text { pertandingan } \\
\text { babak Final. } & \end{array}$ & 420 & Menit & Panitia Pertandingan \\
\hline \multicolumn{3}{|c|}{ J U M L A H } & 2400 & Menit & \\
\hline
\end{tabular}

Unsur-unsur yang terlibat sebagai peserta soaialisasi merupakan unsur yang berasal dari pelatih dan pemain bolavoli, juga para wasit di kecamatan Pulau-Pulau Babar Kabupaten Maluku Barat Daya. Sehingga kegiatan sosialisasi ini dapat berdampak pada terbangunnya pemahaman dasar tentang peraturan, dan Teknik permainan bolavoli pasir, dan bisa melaksanakan berbagai pertandingan disetiap kesempatan. Kontribusi materi-materi yang disajikan dalam kegiatan ini antaralain;

a. Manejemen pertandingan. Materi ini memuat tentang bagaimana menyelenggarakan pertandingan dengan menggunakan system berbagai system pertandingan secara rinci, serta berbagai keuntungan dan kerugian dari setiap system pertandingan yang digunakan, juga bagaimana mengelola administrasi pertandingan. Proses pertandingan bolavoli pasir merupakan cabang olahraga yang baru saja diperkenalkan bagi masyarakat di kecamatan ini. Oleh karenanya berdasarkan berbagai kenyataan yang selama ini tergambar dalam setiap pelaksanaan pertandingan bolavoli indoor, bahwa proses manejemen pertandingannya tidak berjalan sesuai dengan konsep manejemen yang benar, terkesan mengikuti pemahaman manejemen pertandingan bolavoli indoor sekitar tahun 90an. Sehingga lebih banyak melahirkan protes yang berujung keributan bahkan perkelahian dari para peserta pertandingan. Oleh karenanya, Ketika Ketika tim mengadakan sosialisasi terkait manejemen dalam pertandingan bolavoli pasir, diharapkan dapat menghindarkan kekacauan yang terjadi antar pemain (Nurhasan, 1991). 
GANDRUNG: Jurnal Pengabdian Kepada Masyarakat ISSN: 2721-6136 (Online)

b. Bolavoli Pasir dan Perkembangannya, serta Teknik dalam permainan bolavoli pasir. Materi ini memuat tentang sejarah perkembangan permainan bolavoli pasir, dan juga kharakteristik permainan bolavoli pasir. Meskipun hal ini dirasa tidak terlalu maksimal karena dibatasi dengan waktu, namun setidaknya dengan materi yang disajikan dapat membawa dampak positif, dimana jarang sekali para pemain bolavoli pasir melakukan kesalahan dan juga pelanggaran. Selain itu juga dalam Teknik permainan bolavoli pasir dijelaskan juga Teknik permainan yang bisa berdampak pada terjadinya cedera yang bisa dialami oleh para pemain bolavoli jika bermain di atas pasir, karena pada umumnya semua pemain basicnya bolavoli indoor yang bermain diatas pasir yang permukaanya tidak stabil (Souisa, 2015).

c. Garis-garis Besar Manajemen Pembinaan Prestasi Cabang Olahraga Bolavoli Pasir. Bolavoli pasir merupakan cabang olahraga yang baru untuk duni perbolavolian di kecamatan Pulau-Pulau Babar Kabupaten Maluku Barat Daya. Materi Manajemen pembinaan prestasi untuk cabang olahraga bolavoli pasir merupakan upaya untuk menanamkan konsep dasar-dasar kepelatihan secara umum khusus cabang olahraga ini perlu disajikan agar dapat membuka wawasan para pelatih dan para pemain untuk mengonsepkan dan menerapkan pola pembinaan prestasi bolavoli pasir di kecamatan Pulau-Pulau Babar (Prof. Drs. Harsono, 1993), (Dian Ratnasari, 2018).

d. Peraturan Permainan dan Simulasi Pertandingan. karena merupakan cabang olahraga baru di kecamatan ini, maka mendahului simulasi pertandingan, sangat perlu untuk menjelaskan peraturan yang harus diketahui, dipahami, untuk di jalankan saat seorang pemain mengikuti pertandingan. materi ini cukup berdampak bagi para pemain, sehingga saat melakukan simulasi pertandingan kesahan-kesalahan yang dibuat sangatlah minim, bahkan dari awal hingga akhir berlangsung tanpa hambatan.

Selanjutnya, setelah materi tentang peraturan disajikan, maka dilanjutkan dengan pertemuan teknis bagi para pemain dan juga para pelatih. Setelah pertemuan teknis dilaksanakan, maka para pemain siap untuk melakukan simulasi pertandingan pada keesokan harinya, Selasa 18 Juni 2019.

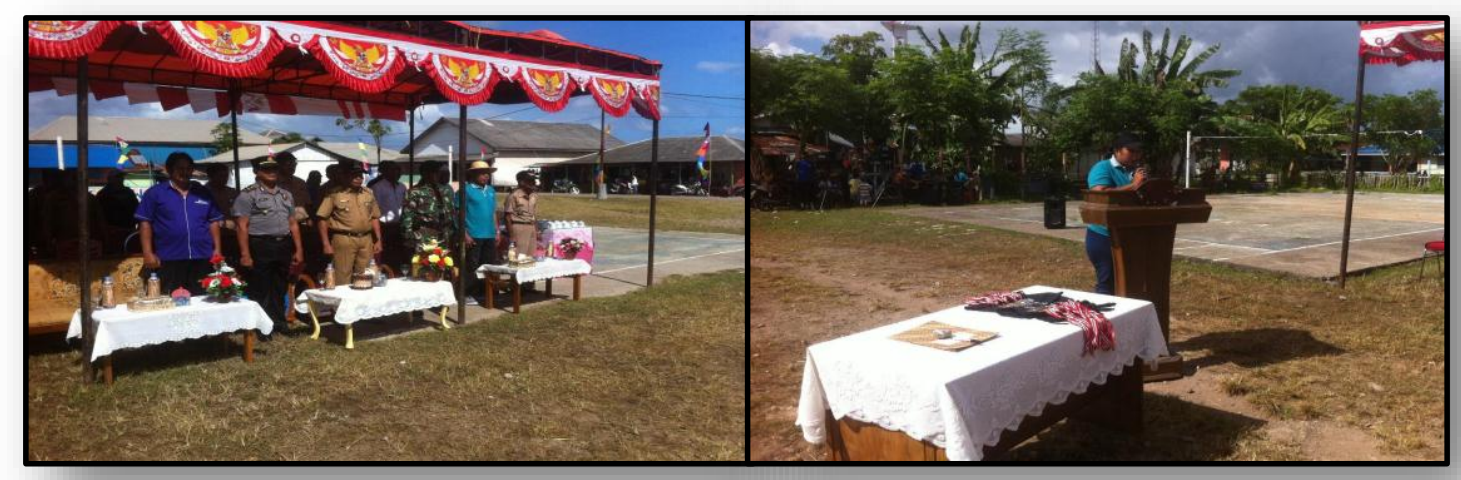

Volume 2, Number 2, Juli 2021 | 245 Socialitation and Simulation Game of the Volleyball Sand Sport in Babar Islands District of Southwest Maluku 
GANDRUNG: Jurnal Pengabdian Kepada Masyarakat ISSN: 2721-6136 (Online)
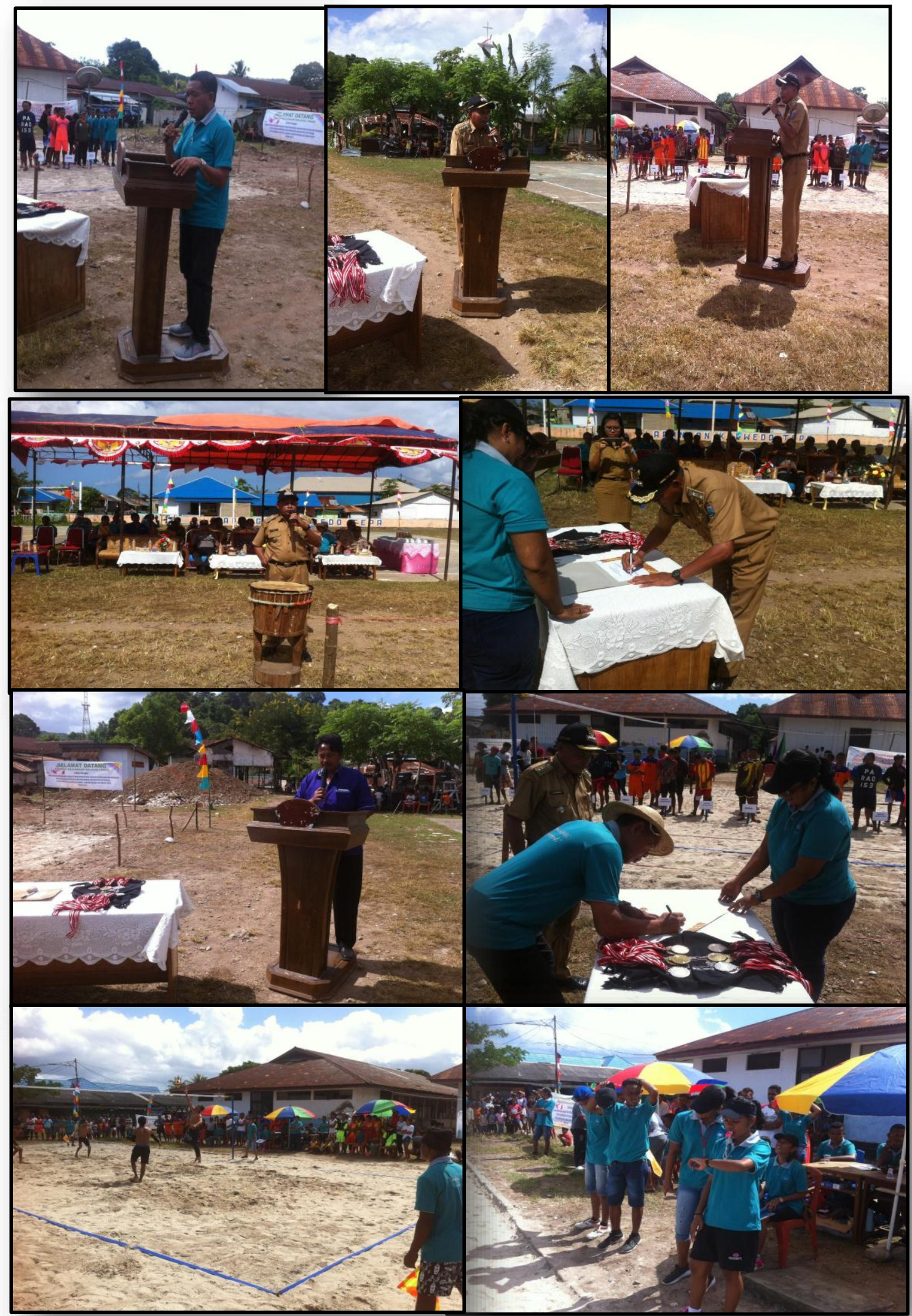

Gambar 3 Rangkaian Kegiatan Pembukaan dilanjutkan Ekshibisi dari UKM Bolavoli Pasir Putera Hotumese

Volume 2, Number 2, Juli $2021 \mid 246$

Socialitation and Simulation Game of the Volleyball Sand Sport in Babar Islands District of Southwest Maluku 
GANDRUNG: Jurnal Pengabdian Kepada Masyarakat ISSN: 2721-6136 (Online)

Dalam rangkaialn acara pembukaan juga peresmian lapangan bolavoli pasir "Lekwaki" sekaligus penandatanganan prasasti lapangan bolavoli (gambar 3) antara Camat Pulau-Pulau Babar, dan Pihak Fakultas Keguruan dan IImu Pendidikan yang diwakili oleh Wakil Dekan Bidang Akademik FKIP Unpatti, yang notabene adalah Pembina UKM Bolavoli Program Studi Pendidikan Jasmani. Penandatanganan turut disaksikan oleh para musyawarah pimpinan kecamatan yang turut serta dalam acara pembukaan. Selanjutnya saat tim pengabdian Kembali ke Ambon, Lapangan Bolavoli pasir beserta peralatan maupun perlenkapan bertanding diserahkan kepada pemerintah kecamatan, untuk digunakan untuk proses pembinaan prestasi bolavoli pasir di daerah kecamatan Pulau-Pulau Babar dan sekitarnya.

Usai rangkaian acara pembukaan dan eksebishi, maka rangkaian kegiatan pun dilanjutkan dengan rangkaian pertandingan. Berdasarkan jumlah peserta yang terdaftar, maka jumlah peserta yang terlibat dalam kegiatan ini sebanyak 26 (dua puluh enam) pasang putera, dan 9 (Sembilan) pasang puteri, yang berasal dari klub-klub bolavoli di kecamatan PP. Babar, kecamatan Babar Timur, dan kecamatan pulau wetang. Dengan rangkaian pertandingan sebanyak 25 (dua puluh lima) pertandingan untuk putera, dan 8 (delapan) pertandingan untuk puteri. Sehingga jumlah pertandingan yang dapat direncanakan oleh panitia sebanyak 33 (tiga puluh tiga) pertandingan, dan dilaksanakan selama 3 (tiga) hari. Sedangkan system pertandingan yang digunakan yaitu "system gugur" menggunakan for ronde, dengan system permainan "two winning set". Selanjutnya alokasi waktu yang disediakan untuk melaksanakan seluruh rangkaian pertandingan bolavoli pasir dalam rangka pengabdian masyarakat kolaborasi dosen dan mahasiswa tahun 2019, yaitu tanggal 18, 19, dan 20 juni 2019, mulai dari jam 08.00 wit. Sampai dengan jam 18.30 wit. Untuk skema atau bagan pertandingan secara lengkap dapat dilihat dalam bagian lampiran dari laporan ini.

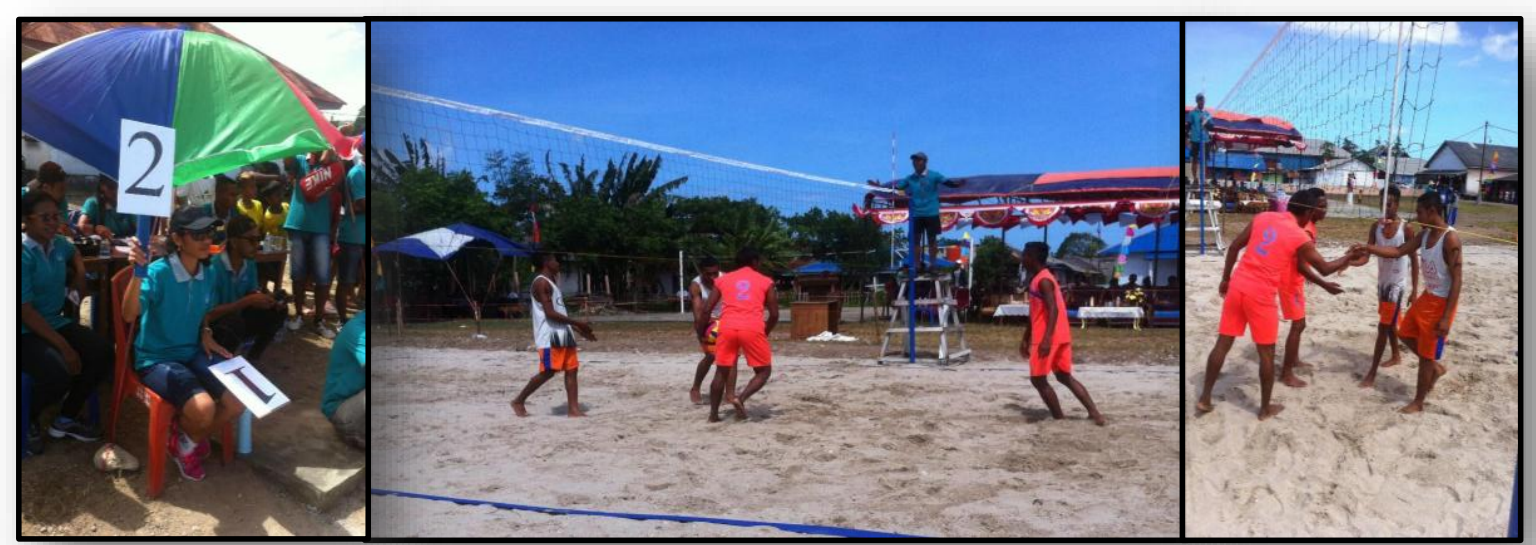




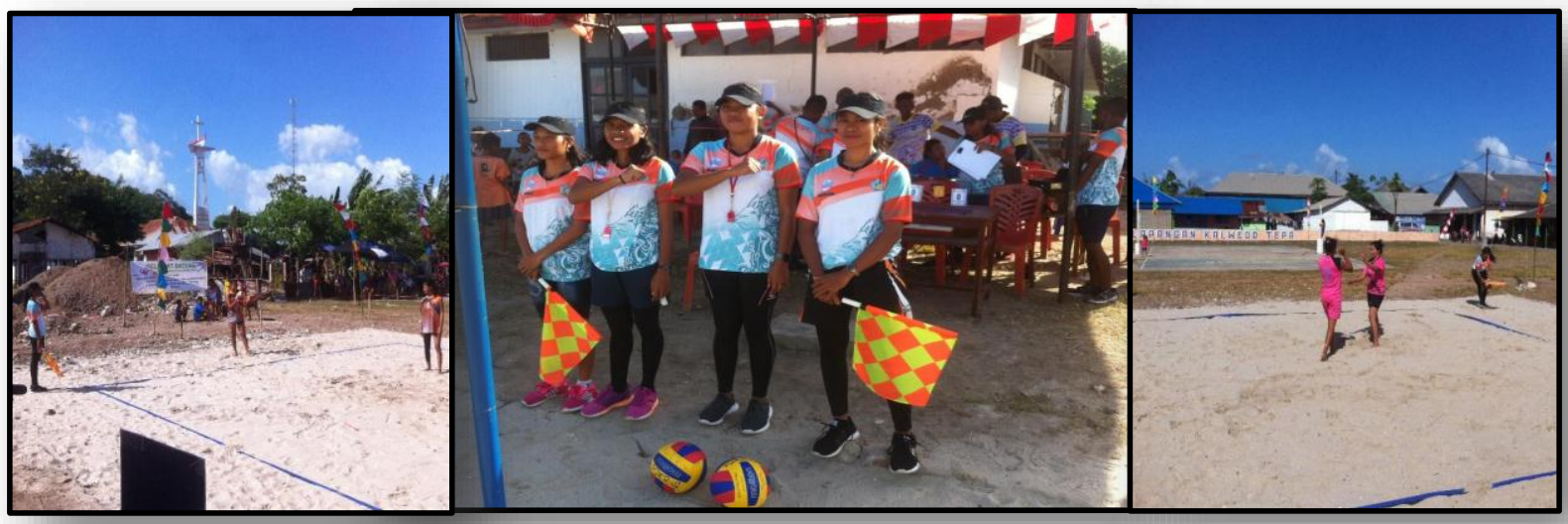

Gambar 4. Beberapa Rangkaian Kegiatan Pertandingan Dalam 3 (tiga) hari

Setelah 25 (dua puluh lima) rangkaian pertandingan putera dan 8 (delapan) pertandingan puteri dilaksanakan selama 3 hari, maka hasil dari total 35 (tiga puluh lima) rangkaian pertandingan putera dan puteri secara rinci dapat digambarkan dalam tabel 4 dan tabel 5 dibawah ini. Untuk 25 (dua puluh lima) rangkaian pertandingan pada pasangan bolavoli pasir putera, yang dilaksanakan dengan system gugur (5 regu bye) maka hasil yang diperoleh adalah sebagai berikut:

Tabel 4.

Hasil Pertandingan Bolavoli Pasir Putera

\begin{tabular}{|c|c|c|l|}
\hline Juara ke- & Medali & Nama Regu & \multicolumn{1}{|c|}{ Nama Pemain } \\
\hline I & Emas & RALMIDA - 1 & $\begin{array}{l}\text { 1. Ahaswerus Relmasira. } \\
\text { 2. Luter Teurupun. }\end{array}$ \\
\hline II & Perak & ARMAS -5 & $\begin{array}{l}\text { 1. Yoram Okimekma. } \\
\text { 2. Kaleb Okimekma. }\end{array}$ \\
\hline III & Perunggu & ARMAS - 2 & $\begin{array}{l}\text { 1. Fernandito Wakim. } \\
\text { 2. Melanton Imurnely. }\end{array}$ \\
\hline IV & -- & ARMAS -4 & $\begin{array}{l}\text { 1. Wempy Okimekma. } \\
\text { 2. Charles Okmemera. }\end{array}$ \\
\hline
\end{tabular}

Selanjutnya, berdasarkan 8 (sembilan) rangkaian pertandingan pada pasangan bolavoli pasir puteri, yang dilaksanakan dengan system gugur (1 pertandingan for ronde) maka hasil yang diperoleh dapat dilihat dalam tabel 5 dibawah ini.

Tabel 5.

Hasil Pertandingan Bolavoli Pasir Puteri

\begin{tabular}{|c|c|c|c|}
\hline Juara ke- & Medali & Nama Regu & Nama Pemain \\
\hline I & Emas & LE K W A K I & 1. Wulandari Taliak \\
\hline
\end{tabular}


GANDRUNG: Jurnal Pengabdian Kepada Masyarakat ISSN: 2721-6136 (Online)

\begin{tabular}{|c|c|c|l|}
\hline & & & 2. Frenska Latue \\
\hline II & Perak & LEKREY & $\begin{array}{l}\text { 1. Fransina Mose } \\
\text { 2. Marthina Mose }\end{array}$ \\
\hline III & Perunggu & SMANSA - 1 & $\begin{array}{l}\text { 1. Angsina Latulola } \\
\text { 2. Diana Walupy }\end{array}$ \\
\hline \multirow{2}{*}{ IV } & - & KENDIS SMILE & $\begin{array}{l}\text { 1. Florensia Taliak } \\
\text { 2. Ecevina Tagarnana }\end{array}$ \\
\hline
\end{tabular}

Peserta yang melaju hingga babak final, mendapatkan medali bagi para pemain dan juga pelatih, juga piagam penghargaan bagi seluruh club dan juga pelatih yang terlibat dalam kegiatan sosialisasi permainan dan simulasi pertandingan bolavoli pasir di kecamatan Pulau-Pulau Babar Kabupaten Maluku Barat Daya.

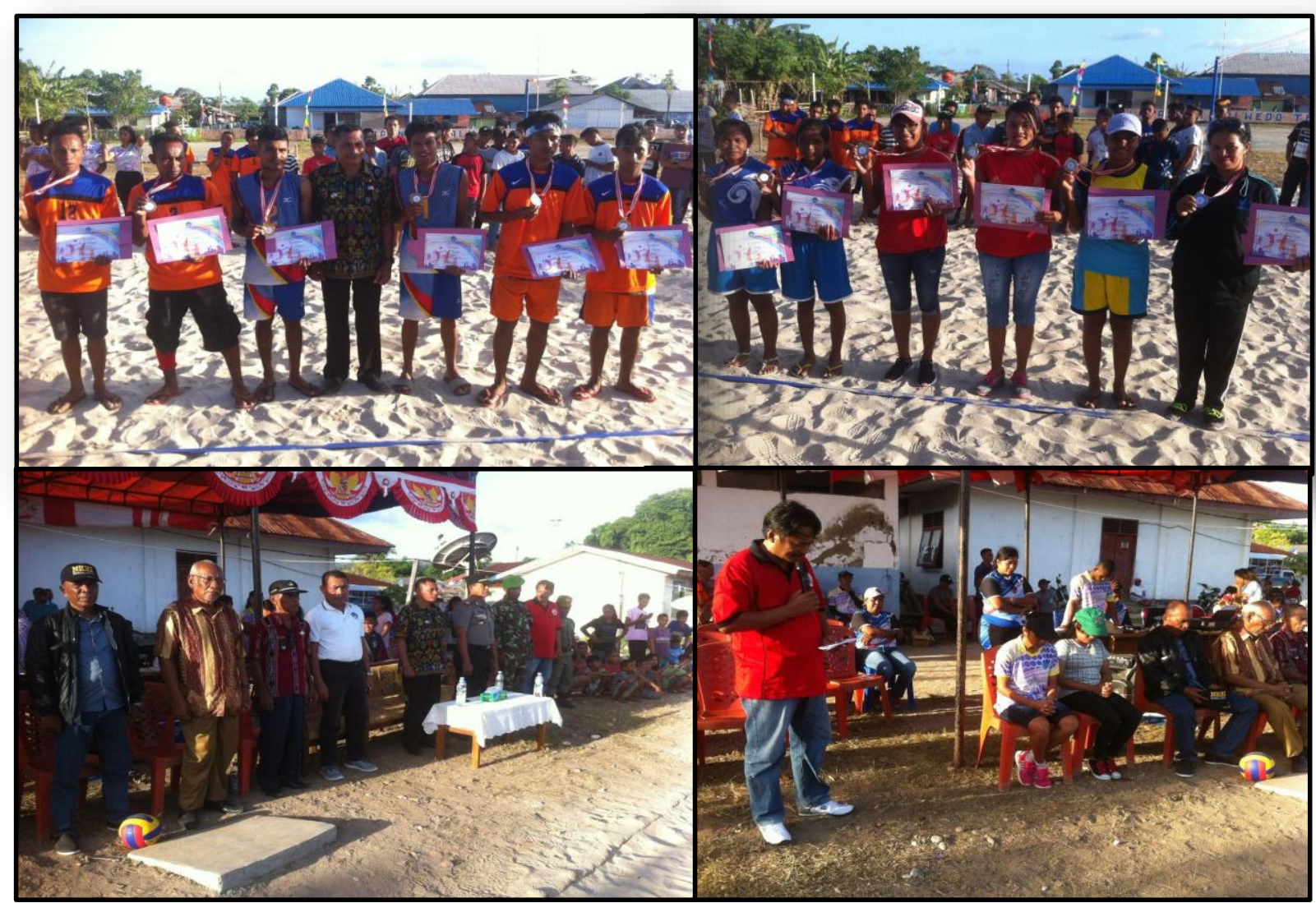

Volume 2, Number 2, Juli 2021 | 249 Socialitation and Simulation Game of the Volleyball Sand Sport in Babar Islands District of Southwest Maluku Regency 
GANDRUNG: Jurnal Pengabdian Kepada Masyarakat ISSN: 2721-6136 (Online)

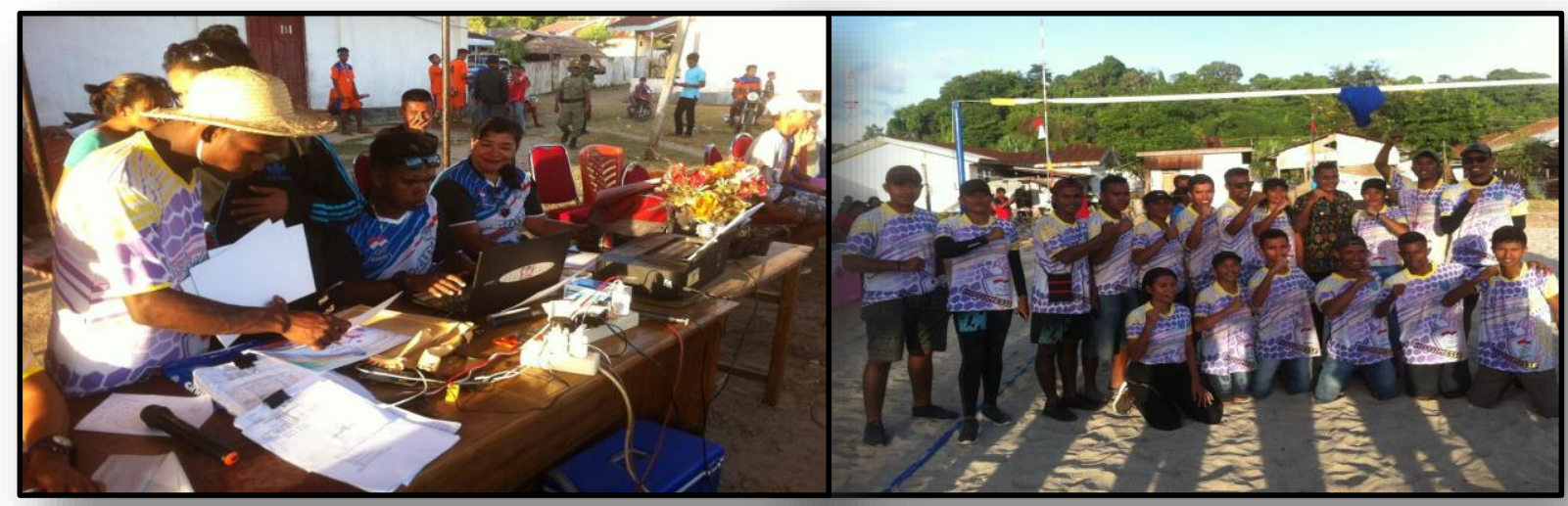

Gambar 5. Rangkaian Acara Penutupan Kegiatan Pertandingan, Serta Pengalungan Medali Bagi Para Pemenang, Serta piagam penghargaan bagi seluruh peserta

\section{Kesimpulan}

Secara umum pengabdian masyarakat kolaborasi dosen dan mahasiswa program studi pendidikan jasmani kesehatan dan rekreasi yang dilaksanakan di desa Tepa, kecamatan Pulau-Pulau Babar, kabupaten Maluku Barat Daya tahun 2019, dengan kegiatan berupa "Sosialisasi peraturan permainan serta simulasi pertandingan bolavoli pasir, yang berlangsung antara tanggal 18, 19, dan 20 Juni 2019, menghasilkan beberapa hal positif antara lain;

1) Pengadaan lapangan bolavoli pasir yang berlokasi di arena olahraga lapangan kalwedo, atas kerjasama dosen dan UK Bolavoli program studi, bersama pihak perusahaan SS, pihak pengusaha (bpk. Jefri Dasmasela, SE), pihak pemerintah kecamatan Pulau-Pulau Babar, dan kepala desa Tepa. Lapangan bolavoli pasir yang telah dikerjakan, telah diresmikan penggunaannya, dengan nama "Lapangan Bolavoli Pasir LEKWAKI", merupakan lapangan bolavoli pasir ke-2 di provinsi Maluku, setelah lapangan bolavoli pasir universitas Pattimura Ambon. Selain itu, semua fasilitas pertandingan selain lapangan, seperti; (a) line bolavoli pasir, (b) net bolavoli pasir, (c) roads, (d) bolavoli pasir, dan (e) bendera linesman, telah diserahkan secara resmi dengan berita acara penyerahan peralatan pertandingan Bolavoli Pasir nomor: 01/BA/PKM/PJKR/V/2019, dan berita acara penerimaan Peralatan Pertandingan Bolavoli Pasir nomor: 02/BA/PKM/PJKR/V/2019, yang ditandatangani oleh camat Pulau-Pulau Babar Kabupaten Maluku Barat Daya, dengan wakil dekan bidang akademik FKIP Universitas Pattimura Ambon.

2) Permainan bolavoli yang sebelumnya samasekali belum pernah dikenal oleh pemain bolavoli di kecamatan Pulau-Pulau Babar, malah cukup mendapat respons positif dan animo dari masyarakat olahraga khusus bolavoli. Hal ini dapat dilihat dari jumlah regu atau pasangan bolavoli yang terdaftar sebagai peserta dalam simulasi pertandingan, meskipin hadiah yang diberikan hanya berupa medali dan sertifikat dari panitia pengabdian masyarakat kolaborasi. 
GANDRUNG: Jurnal Pengabdian Kepada Masyarakat ISSN: 2721-6136 (Online)

3) Setelah permainan ini disosialisasikan di kecamatan Pulau-pulau Babar dan sekitarnya, maka respons positif telah disampaikan oleh pimpinan kecamatan, bahwa cabang olahraga bolavoli pasir akan diagendakan sebagai salah satu cabang yang dipertandingkan disetiap musim pertandingan, seperti menjelang 17 agustus dan peringatan hari olahraga nasinal di kecamatan Pulau-Pulau Babar, Kabupaten Maluku Barat Daya.

\section{Daftar Referensi}

Afri Rizka Nugraheni, S. R. (2017). Evaluasi Pembinaan Olahraga Prestasi Bolavoli Pantai Puteri Klub Ivojo (Ikatan Voli Ngembalrejo) di Kabupaten Kudus Tahun 2016. Jurnal of Physical Education and Sports. Volume 6 No.3. p-ISSN: 2252-648X. e-ISSN: 2502-4477 , 225-231.

Dian Ratnasari, J. T. (2018). Evaluasi Program Pemusatan Latihan Daerah (PELATDA) Bolavoli Pasir Puteri DKI Jakarta. Jurnal IImiah Sport Coaching and Education. Volume 2, 8-16.

Gambaran Umum Kondisi Wilayah Maluku Barat Daya. (2018). Retrieved from Kabupaten Maluku Barat Daya:https://sippa.ciptakarya.pu.go.id/sippa_online/ws_file/dokumen/rpi2jm/DOCRPIJM_755fbcc c6c_BAB\%20IIBAB\%202_Gambaran\%20Umum\%20Kondisi\%20Wilayah-\%20MBD.pdf

Nurhasan. (1991). Manuasia dan Olah Raga. Seri Bahan Kuliah Olahraga ITB. Bandung: ITB dan FPOK/IKIP Bandung.

Prof. Drs. Harsono, M. (1993). Latihan Kondisi Fisik. In Seri Bahan Penataran (pp. 1-46). Jakarta: Komite Olahraga Nasional Indonesia Pusat (KONI PUSAT), Pusat Pendidikan dan Penataran.

Souisa, M. (2015, Juni). Identifikasi Faktor-Faktor Risiko Cedera Terhadap Teknik Lompatan dan Pendaratan Atlet Bolavoli Pantai Puteri Kota Ambon. Vol. 1, No. 1. ISSN: 2443-1206, pp. 103-116. 